\title{
Genetic refinement and physical mapping of a chromosome 18q candidate region for bipolar disorder
}

\author{
Geert R Verheyen ${ }^{1}$, Sandra M Villafuerte ${ }^{1}$, Jurgen Del-Favero ${ }^{1}$, Daniel Souery ${ }^{2}$, \\ Julien Mendlewicz ${ }^{2}$, Christine Van Broeckhoven ${ }^{3}$ and Peter Raeymaekers ${ }^{1}$ \\ ${ }^{1}$ Department of Molecular Genetics, Laboratory of Psychogenetics, Flanders Interuniversity Institute for \\ Biotechnology (VIB), University of Antwerp (UIA), Department of Biochemistry, Antwerp, Belgium \\ ${ }^{2}$ Department of Psychiatry, Erasme Hospital, University of Brussels (ULB), Brussels, Belgium \\ ${ }^{3}$ Department of Molecular Genetics, Flanders Interuniversity Institute for Biotechnology (VIB) and Laboratory of \\ Neurogenetics, Born-Bunge Foundation (BBS), University of Antwerp (UIA), Department of Biochemistry, Antwerp, \\ Belgium
}

\begin{abstract}
Recent genetic studies have implicated chromosome 18 in bipolar disorder (BP) with putative loci in the pericentromeric region and on 18q. We reported linkage to chromosome 18q21.33-q23 in a large family. In this study we typed additional markers in the family and were able to reduce the candidate region significantly. All affected family members are sharing alleles for markers spanning a genetic distance of maximal $8.9 \mathrm{cM}$. Haplotype analysis provided a marker order in agreement with published genetic and physical maps. Using yeast artificial chromosomes, we constructed a contig map that will help to identify positional candidate genes for bipolar disorder.
\end{abstract}

Keywords: bipolar disorder; chromosome 18; linkage; haplotype analysis; YAC; YAC-contig

\section{Introduction}

Bipolar disorder (BP) is a severe psychiatric condition that is characterised by disturbances in mood, ranging from an extreme state of elation (mania) to a severe state of dysphoria (depression). Two types of bipolar illness have been described: type I BP illness (BPI) is characterised by major depressive episodes alternating with phases of mania, and type II BP illness (BPII) by

Correspondence: Professor Dr C Van Broeckhoven, Department of Molecular Genetics, Flanders Interuniversity Institute for Biotechnology (VIB) and Laboratory of Neurogenetics, Born-Bunge Foundation (BBS), University of Antwerp (UIA), Department of Biochemistry, Universiteitsplein 1, B-2610 Antwerp, Belgium. Tel: + 323820 2601; Fax: +32 3820 2541; E-mail: cvbroeck@uia.ac.be

Received 25 September 1998; revised 10 December 1998; accepted 30 December 1998 major depressive episodes alternating with phases of hypomania. Relatives of BP probands have an increased risk of BP, unipolar disorder - patients only experiencing recurrent depressive episodes (UP), and cyclothymia - minor depression and hypomania episodes (CY). Schizoaffective disorders of the manic (SAm) and depressive (SAd) type also exhibit symptoms compatible with mood disorders. Based on these observations BP, CY, UP and SA are classified as BP spectrum disorders. The involvement of genetic factors in the etiology of BP spectrum disorders has been suggested by family, twin and adoption studies. ${ }^{1}$ However, the exact pattern of transmission is unknown. In some studies, complex segregation analysis supports the existence of a single major locus for $\mathrm{BP}^{2}$ Other researchers propose a liability threshold model, in which the liability to develop the disorder results from 
the additive combination of multiple genetic and environmental effects. ${ }^{3}$

Due to the complex mode of inheritance, parametric and nonparametric linkage strategies are applied in families in which BP disorder appears to be transmitted in a Mendelian fashion. Early linkage findings on chromosomes $11 \mathrm{p} 15^{4}$ and Xq27-q28 ${ }^{5,6}$ have been controversial and could initially not be replicated. ${ }^{7,8}$ In more recent studies, evidence or suggestive evidence for linkage to particular regions on chromosomes 4,12 , 18,21 and $\mathrm{X}$ was found. ${ }^{9-13}$ In order to test the validity of the reported linkage results, these findings have to be replicated in independent studies.

Recently, linkage of BP to the pericentromeric region on chromosome 18 was reported. ${ }^{11}$ The $18 p$ linkage was replicated by Stine et $a l^{14}$ who also reported suggestive evidence for a locus on 18q21.2-q21.32 in the same study. In a replication study, we tested linkage with chromosome 18 markers in 10 Belgian families with a $\mathrm{BP}$ proband. In one out of 10 families (MAD31), we found suggestive linkage with markers located at 18q21.33-q23. ${ }^{15}$ Multipoint linkage analysis gave the highest lod score in the interval between D18S51 and D18S61, with a maximum lod score of +1.34 . An affected sib-pair analysis also rejected the null-hypothesis of nonlinkage for several of the markers tested. At the 1997 (Sante Fe, USA) and the 1998 World Congress on Psychiatric Genetics (Bonn, Germany), several other groups also reported evidence for linkage of BP to $18 \mathrm{p}$ and $18 \mathrm{q} .{ }^{16-21}$ Considering the complexity of BP disorder and the different methodologies applied, the independent studies focusing on 18q21-q23 might reflect the presence of the same susceptibility gene. In particular the regions implicated by Coon et $a l,{ }^{17}$ McInnes et al, ${ }^{20}$ McMahon et al ${ }^{21}$ overlap partially with the candidate region derived by us. ${ }^{15}$ These data encouraged us to study the $18 \mathrm{q}$ region in more detail, by refining the candidate region in family MAD31 and by constructing a physical map of the region.

\section{Materials and Methods}

\section{Family Data}

The pedigree and the clinical diagnoses in family MAD31, a Belgian family with a BPII proband, were described in detail elsewhere. ${ }^{15}$ In this study, only the 15 family members who were informative for linkage analysis were selected for additional genotypings (Figure 1 ). The different clinical diagnoses in family MAD31 are as follows: one BPI, one BPII, two UP, four major depressive disorder (MDD), one SAm and one SAd.

\section{Genotyping of Family Members}

All short tandem repeat (STR) genetic markers used in this study were obtained from several sources on the internet: Genome DataBase (GDB; http://www.gdb.org/), GenBank (http://www.ncbi.nlm.nih.gov/), Cooperative Human Linkage Center (CHLC; http://www.chlc.org/), Eccles Institute of Human Genetics (EIHG; http://www.genetics.utah.edu/) and Généthon (http://www.genethon.fr/).

\section{Lod Score Analysis}

Two-point lod scores were calculated for three different disease models using Fastlink 2.2. ${ }^{22}$ For all models, a disease gene frequency of $1 \%$ and a phenocopy rate of $1 / 1000$ was used. Model 1 included all clinically affected patients and all healthy individuals, with the healthy individuals assigned a disease penetrance depending on their age at examination. The penetrance curve was calculated based on mean age at onset in the pedigree with a maximum penetrance of $70 \%$ for the oldest age class ( $>60$ year). Model 2 is similar to model 1 , but patients were assigned a diagnostic stability score, calculated based on clinical data such as the number of episodes, the number of symptoms during the worst episode and history of treatment. ${ }^{23,15}$ Model 3 is as model 1 but includes only patients.

\section{STS Content Mapping and Construction of the YAC Contig}

For construction of the YAC-contig spanning the chromosome $18 \mathrm{q}$ candidate region, the data of the STS-based physical map ${ }^{24}$ was consulted on the Whitehead Institute for Biomedical Research (WI; http://www-genome.wi.mit.edu/) Internet site. YACs were obtained from the YAC Screening Centre Leiden (YSCL, Leiden, the Netherlands) and from CEPH (Paris, France). The YAC clones were grown and DNA was extracted using standard procedures. ${ }^{25}$ YACs were investigated for the presence of STSs between D18S51 and D18S61 by a 40 cycles touchdown PCR protocol. YAC sizes were determined by pulsed field gel electrophoresis (PFGE) from embedded total yeast DNA.

\section{Determination of YAC End Sequences}

YAC end sequences were determined using an inverse PCR protocol. Two $\mu \mathrm{g}$ YAC DNA was digested simultaneously with RsaI and SspI in a total volume of $30 \mu \mathrm{l}$ and was subsequently heated to $68^{\circ} \mathrm{C}$ for $30 \mathrm{~min}$. Five $\mu \mathrm{l} 10 \times$ ligase buffer, $1 \mu \mathrm{l} 100 \mathrm{~mm}$ ATP, $64 \mu \mathrm{l} \mathrm{H}_{2} \mathrm{O}$ and $1 \mathrm{U}$ ligase was added and the sample was incubated overnight at room temperature. The sample was heated to $68^{\circ} \mathrm{C}$ for $30 \mathrm{~min}$, cooled and then mixed with 5-10 U of FspI (left arm) or 5-10 U SmaI (right arm). Digestion was allowed for at least 2 hours and the sample was heated to $68^{\circ} \mathrm{C}$ for $30 \mathrm{~min}$ and cooled to room temperature. $1 \mu \mathrm{l}$ of this sample was used in a $25-50 \mu \mathrm{l} \mathrm{PCR}$ using the appropriate primers (left YAC end: 161: 5'-CGATGCTGTCGGAATGGACGATATC-3' and 1207: 5'-AGCCAAGTTGGTTTAAGGCGCAAGACT-3' right YAC end: 162: 5'- GCATGTCTCCATTCACTTCCCAGAC3' and 1208: 5'- TCGAACGCCCGATCTCAAGATTACG$\left.3^{\prime}\right)$ for 30 cycles using the following cycle conditions: denaturation at $94^{\circ} \mathrm{C}$ for $1 \mathrm{~min}$, annealing at $65^{\circ} \mathrm{C}$ for $1 \mathrm{~min}$ elongation at $72^{\circ} \mathrm{C}$ for $2 \mathrm{~min}$. The PCR products were purified and cycle sequenced with one of the amplification primers. Sequences were analysed on an automated DNA sequencer model ABI377 (Applied Biosystems, Foster City, USA) with 


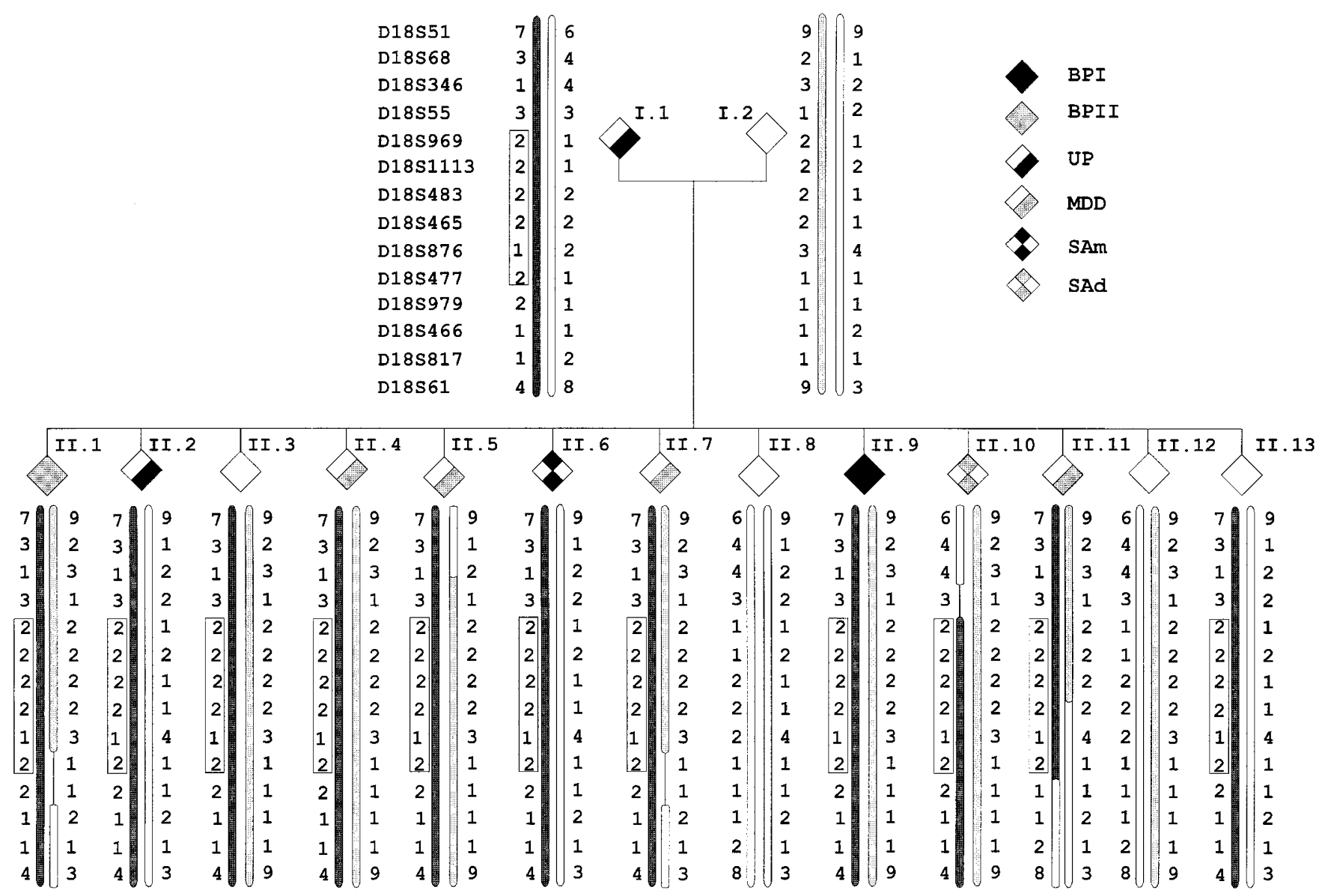

Figure 1 Haplotype analysis in family MAD31. Boxed haplotypes represent the risk haplotype. The father was not informative for three markers, the mother was not informative for five markers.

the fluorescent dye terminator system. Primer sets were designed based on the sequence data of the YAC ends and were used to identify the chromosomal localisation of each YAC end by PCR screening of a monochromosomal mapping panel. ${ }^{26}$ Primer sets located on chromosome 18 were used to verify overlaps among YACs.

\section{Results}

\section{Ordering of the Markers}

Twelve genetic markers, previously located between D18S51 and D18S61, were tested for co-segregation with BP spectrum disorders in family MAD31. The parental haplotypes were reconstructed from genotype information of the siblings in family MAD31 and minimalising the number of possible recombinants (Figure 1). Haplotypes in family MAD31 suggested the following order for the genetic markers: cen[S51-S68-S346]-S55-S969-S1113-S483-S465]-[S876S477]-S979-[S466-S817-S61]-tel. The order relative to each other of the markers between brackets could not be inferred from our data. The marker order in family MAD31 was compared with the marker orders obtained using different mapping techniques (Table 1). D18S68, common to all three maps, was taken as the map anchor point, and the genetic distance in $\mathrm{cM}$ or $\mathrm{cR}$ of the other markers relative to D18S68 are given. Our marker order is in good agreement with the order of the markers on the published chromosome 18 radiation hybrid $\mathrm{map}^{27}$ and the WI YAC contig map. However, a few discrepancies with other maps were observed. The only discrepancy with the Généthon genetic map is the reversed order of D18S465 and D18S477. We mapped D18S346 above D18S55 based on maternal haplotypes, but on the Marshfield map (http://www.marshmed.org/ genetics/) D18S346 was located between D18S483 and D18S979. Also, we placed D18S817 below D18S979, but on the Marshfield map this marker is located between D18S465 and D18S477. However, our location of D18S346 and D18S817 is in agreement with the 
Table 1 Comparison of the order of the markers within the $18 \mathrm{q}$ candidate region for BP spectrum disorder, among several maps

\begin{tabular}{lccc}
\hline Marker $^{\mathrm{a}}$ & \multicolumn{2}{c}{$\begin{array}{c}\text { Genetic maps } \\
\text { Généthon }\end{array}$} & $\begin{array}{c}\text { Rarshfield } \\
\text { (Giacalone }^{27} \text { ) }\end{array}$ \\
\hline D18S51 & & $(-) 3.4 \mathrm{cM}$ & $(-) 27.9 \mathrm{cR}$ \\
D18S68 & $0 \mathrm{cM}$ & $0 \mathrm{cM}$ & $0 \mathrm{cR}$ \\
D18S346 & & $5.3 \mathrm{cM}$ & $52.2 \mathrm{cR}$ \\
& & $0 \mathrm{cM}$ & $72.5 \mathrm{cR}$ \\
D18S55 & $0.1 \mathrm{cM}$ & $0.6 \mathrm{cM}$ & \\
D18S969 & & & \\
D18S1113 & $0.7 \mathrm{cM}$ & $3.2 \mathrm{cM}$ & $88 \mathrm{cR}$ \\
D18S483 & $2.5 \mathrm{cM}$ & $5.3 \mathrm{cM}$ & $101.3 \mathrm{cR}$ \\
D18S465 & $4.5 \mathrm{cM}$ & & \\
& & & \\
D18S876 & & $5.3 \mathrm{cM}$ & $166.4 \mathrm{cR}$ \\
D18S477 & $4.4 \mathrm{cM}$ & & \\
& & $8.9 \mathrm{cM}$ & \\
D18S979 & & & \\
D18S466 & $7.6 \mathrm{cM}$ & $11.1 \mathrm{cM}$ & $212.4 \mathrm{cR}$ \\
D18S61 & $8.4 \mathrm{cM}$ & $11.8 \mathrm{cM}$ & $249.5 \mathrm{cR}$ \\
D18S817 & & $5.3 \mathrm{cM}$ & $260.6 \mathrm{cR}$ \\
\hline
\end{tabular}

${ }^{\mathrm{a}}$ Order according to haplotyping results in family MAD31; (-) Marker is located proximal of D18S68.

chromosome 18 radiation hybrid map of Giacalone et $a l .{ }^{27} \mathrm{~A}$ discrepancy was also observed with the WI radiation hybrid map, in which D18S68 was located below D18S465. However, our maps as well as others placed this marker above D18S55.

\section{Lod score Analysis and Refinement of the Candidate Region}

Lod score analysis gave positive results with all markers, confirming our previous observation that 18q21.33-q23 is implicated in BP spectrum disorders, at least in family MAD31. ${ }^{15}$ Summary statistics of the analysis under all models are given in Table 2. The highest two-point lod score $(+2.01$ at $\theta=0.0)$ was obtained with markers D18S1113, D18S876 and D18S477 under model 1 in the absence of recombinants (Table 2). In model1, all individuals with a BP spectrum disorder are considered affected and contribute fully to the linkage analysis.

Before the fine mapping, the candidate region was flanked by D18S51 and D18S61, which are separated by a genetic distance of $15.2 \mathrm{cM}$ on the Marshfield map. The informative recombinants with D18S51 and D18S61 were observed in two affected individuals (II.10 and II.11 in Figure 1). However, since no other markers were tested within the candidate region it was not known whether these individuals shared a region identical-by-descent (IBD). The additional genetic mapping data indicates that all affected individuals are sharing alleles at D18S969, D18S1113, D18S876 and D18S477 (Figure 1, boxed haplotype). Also alleles from markers D18S483 and D18S465 are probably IBD, but these markers were not informative in the affected parent I.1. A proximal recombination occurred between D18S68 and D18S969. We could not use D18S346 in refining the candidate region, because its exact location is not known. A distal recombination occurred between D18S477 and D18S979. Based on these results the candidate region is reduced by $8.9 \mathrm{cM}$ between D18S68 and D18S979.

\section{Construction of the YAC Contig}

According to the WI integrated map $56 \mathrm{CEPH}$ megaYACs are located in our initial candidate region

Table 2 Summary statistics of the two-point lod scores in family MAD31

\begin{tabular}{lccccccccc}
\hline Marker & \multicolumn{3}{c}{ Model 1 } & \multicolumn{3}{c}{ Model 2 } & \multicolumn{3}{c}{ Model 3 } \\
& $\mathrm{Z}$ at $\theta=0.0$ & $\mathrm{Z}_{\max }$ & $\theta_{\max }$ & $\mathrm{Z}$ at $\theta=0.0$ & $\mathrm{Z}_{\max }$ & $\theta_{\max }$ & $\mathrm{Z}_{\text {at }} \theta=0.0$ & $\mathrm{Z}_{\max }$ & $\theta_{\max }$ \\
\hline D18S51 & -0.19 & 0.73 & 0.1 & 0.94 & 0.94 & 0.01 & 0.08 & 0.54 & 0.1 \\
D18S68 & -0.19 & 0.73 & 0.1 & 0.94 & 0.94 & 0.01 & 0.07 & 0.55 & 0.1 \\
D18S346 & -0.19 & 0.73 & 0.1 & 0.94 & 0.94 & 0.01 & 0.07 & 0.55 & 0.1 \\
D18S69 & 1.40 & 1.40 & 0.0 & 1.27 & 1.27 & 0.0 & 1.20 & 1.20 & 0.0 \\
D18S1113 & 2.01 & 2.01 & 0.0 & 1.87 & 1.87 & 0.0 & 1.77 & 1.77 & 0.0 \\
D18S876 & 2.01 & 2.01 & 0.0 & 1.87 & 1.87 & 0.0 & 1.77 & 1.77 & 0.0 \\
D18S477 & 2.01 & 2.01 & 0.0 & 1.87 & 1.87 & 0.0 & 1.77 & 1.77 & 0.0 \\
D18S979 & -0.18 & 0.77 & 0.1 & 1.08 & 1.08 & 0.0 & 0.08 & 0.54 & 0.0 \\
D18S817 & -0.19 & 0.73 & 0.1 & 1.08 & 1.08 & 0.0 & 0.07 & 0.55 & 0.1 \\
D18S61 & -0.21 & 0.73 & 0.1 & 1.08 & 1.08 & 0.0 & 0.07 & 0.54 & 0.1 \\
\hline
\end{tabular}

D18S55, D18S483, D18S465 and D18S466 were not informative. 
contained between D18S51 and D18S61. ${ }^{28,15}$ We selected those YACs that were located between D18S60 and D18S61 and that contained at least one chromosome 18STS. D18S51 is not present on the WI map, but is located $2.3 \mathrm{cM}$ distal of D18S60 (Genetic Location Database: http://cedar.genetics.soton.ac.uk/pub). To limit the number of potential chimeric YACs, we eliminated YACs that were also positive for nonchromosome 18 STSs. All selected YACs were tested for STSs and STRs mapped between D18S60 and D18S61 and positive YACs were assembled in a YAC contig map. Three gaps remained in the YAC contig of which one was located in the refined candidate region between D18S876 and GCT3G01. For this region additional YACs were obtained and analysed for STSs and STRs surrounding the gap, but no overlaps were observed. Furthermore, it was not known which of the selected YACs were chimeric. Therefore end sequences from seven YACs covering the candidate region were determined (Table 3 ) using the inverse PCR protocol and mapped using a somatic cell hybrid panel. YACs 961-h-9, 942-c-3 and 766-f-12 are not chimeric. YACs 717-d-3, 731-c-7 and 907-e-1 had positive hits with other chromosomes and are chimeric. The newly developed STSs SV10R (right-arm of 942-c-3), SV11R (right-arm of 766-f-12) and SV31L (left-arm of $752-\mathrm{g}-8)$ are located within the gap and successfully detected overlaps among YACs flanking the gap. The final YAC contig is shown in Figure 2, in which we represented only the YACs that had unambiguous positive hits with the chromosome 18 STSs. In a few cases weak positive signals were also obtained with some YACs which probably represent false positive results. However, these signals did not influence the alignment of the YACs in the YAC contig. The order of the markers provided by the YAC contig map is in complete agreement with the marker order provided by the WI integrated map. ${ }^{24}$ The YAC contig map also confirms the order of the STR markers as suggested by the haplotype analysis in MAD31. Moreover, the YAC

Table 3 Characteristics of end sequences of 7 YACs

\begin{tabular}{|c|c|c|c|}
\hline$Y A C$ & $\begin{array}{l}\text { Arm/size } \\
\text { (bp) }\end{array}$ & Primer sequences & Chimerism \\
\hline $961 \mathrm{~h} 9$ & $\begin{array}{l}\text { left } \\
\text { right } / 122\end{array}$ & $\begin{array}{l}\text { no primers, sequence identified as D18S82 } \\
\text { SV6R-A: TTG TGG AAT GGC TAA GT } \\
\text { SV6R-B: GAA AGT ATC AAG GCA GTG }\end{array}$ & $\begin{array}{l}\text { No } \\
\text { No, located between WI-2620 and WI-4211 }\end{array}$ \\
\hline $942 c 3$ & right/135 & $\begin{array}{l}\text { SV10L-A: TCA CTT GGT TGG TTA ACA TTA CT } \\
\text { SV10L-B: TAG AAA AAC AGT TGC ATT TGA TAT } \\
\text { SV10R-A: AAC CCA AGG GAG CAC AAC TG } \\
\text { SV10R-B: GGC AAT AGG CTT TCC AAC AT }\end{array}$ & $\begin{array}{l}\text { No, located between GATA-p6051 and } \\
\text { D18S968 }\end{array}$ \\
\hline $766 f 12$ & right/119 & $\begin{array}{l}\text { SV11L-A: CTA TGC TCT GAT CTT TGT TAC TTT } \\
\text { SV11L-B: ATT AAC GGG AAA GAA TGG TAT } \\
\text { SV11R-A: AAG GTA TAT TAT TTG TGT CG } \\
\text { SV11R-B: AAA CTT TTC TTA ACC TCA TA }\end{array}$ & $\begin{array}{l}\text { No, located between GATA-p6051 and } \\
\text { D18S968 } \\
\text { No, located between D18S876 and GCT3G01 }\end{array}$ \\
\hline $731 \mathrm{c} 7$ & $\begin{array}{l}\text { left } / 72 \\
\text { right/136 }\end{array}$ & $\begin{array}{l}\text { SV25L-A: AAA TCT CTT AAG CTC ATG CTA GTG } \\
\text { SV25L-B: CCT GCC TAC CAG CCT GTC } \\
\text { SV25R-A: TGG GGT GCG CTG TGT TGT } \\
\text { SV25R-B: GAG ATT TCA TGC ATT CCT GTA AGA }\end{array}$ & $\begin{array}{l}\text { Unknown, no clear hits } \\
\text { Yes, positive hit on chromosome } 1\end{array}$ \\
\hline $907 \mathrm{e} 1$ & left/154 & $\begin{array}{l}\text { SV26L-A: TAT TTG GTT TGT TTG CTG AGG T } \\
\text { SV26L-B: CAA GAA GGA TGG ATA CAA ACA AG } \\
\text { SV26R-A: CGC TAT GCA TGG ATT TA } \\
\text { SV26R-B: GCT GAA TTT AGG ATG TAA }\end{array}$ & $\begin{array}{l}\text { Yes, positive hit on chromosome } 13 \\
\text { Unknown, no clear hits }\end{array}$ \\
\hline $752 \mathrm{~g} 8$ & $\begin{array}{l}\text { left } / 178 \\
\text { right } / 131\end{array}$ & $\begin{array}{l}\text { SV31L-A: GAG GCA CAG CTT ACC AGT TCA } \\
\text { SV31L-B: ATT CAT TTT CTC ATT TTA TCC } \\
\text { SV31R-A: CAA GAT TAT GCC TCA ACT } \\
\text { SV31R-B: TAA GCT CAT AAT CTC TGG A }\end{array}$ & $\begin{array}{l}\text { No, located between D18S876 and GCT3G01 } \\
\text { Unknown, no clear hits }\end{array}$ \\
\hline $717 \mathrm{~d} 3$ & $\begin{array}{l}\text { left } / 98 \\
\text { right } / 244\end{array}$ & $\begin{array}{l}\text { SV34L-A: TCT ACA CAT ATG GGA AAG CAG GAA } \\
\text { SV34L-B: GCT GGT GGT TTT GGA GGT AGG } \\
\text { SV34R-A: ATA AGA GAC CAG AAT GTG ATA } \\
\text { SV34R-B: TCT TTG GAG GAG GGT AGT C }\end{array}$ & $\begin{array}{l}\text { No } \\
\text { Yes, positive hit on chromosome } 1\end{array}$ \\
\hline
\end{tabular}




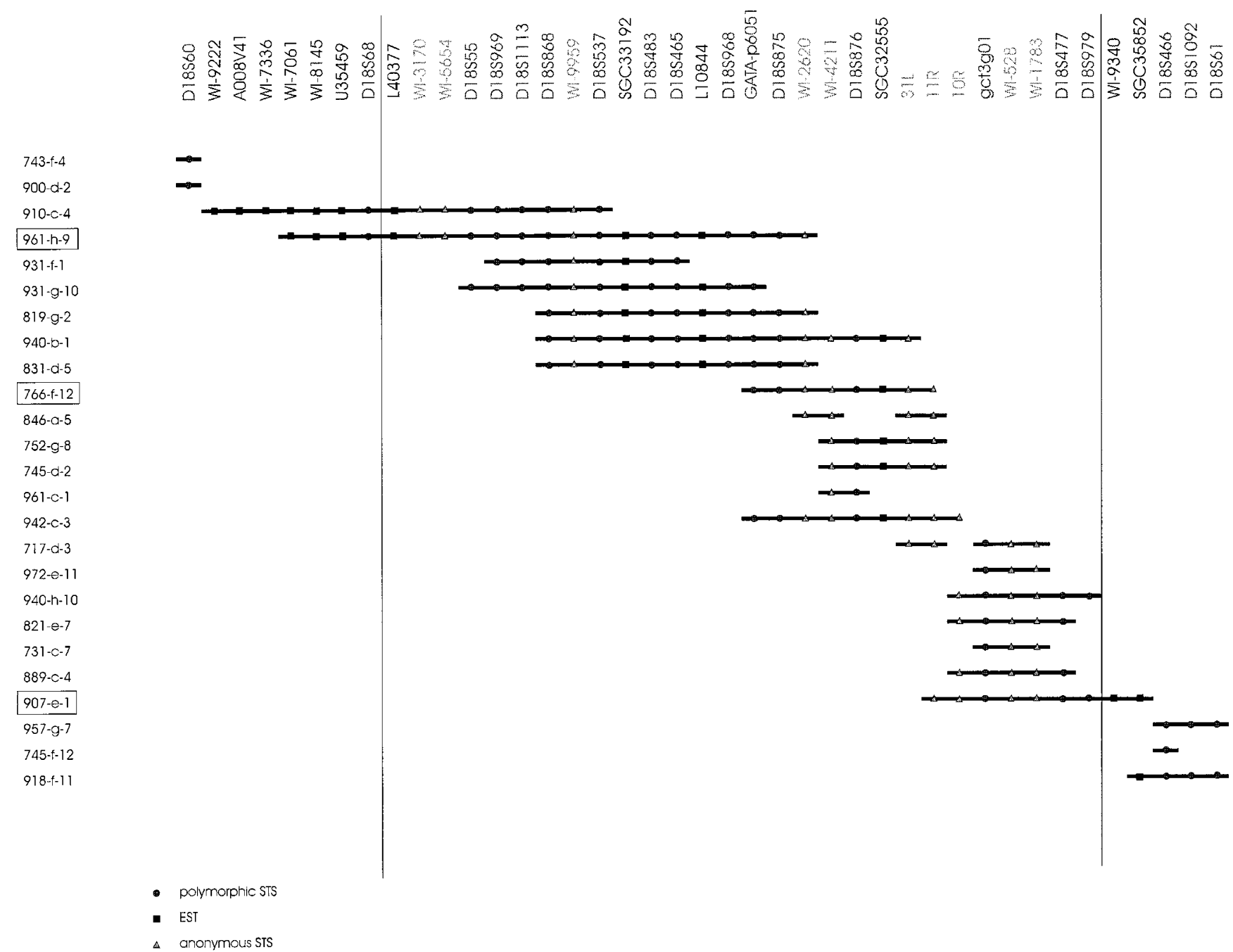

Figure 2 STS content mapping of YACs spanning the candidate region. Black lines represent the YACs. Circles, squares and triangles represent hits with a short tandem repeat sequence (STR), EST and an STS respectively. All information concerning the YACs and STSs was found on the WI, GDB and GenBank Internet sites. Boxed YAC Id's represent YACs comprising the minimum tiling path. The refined candidate region is flanked by the vertical lines.

contig map provides additional information on the relative order of the markers. Together, the haplotype data and the YAC contig provide the following order of markers: [S51-S68-S346]-S55-[S969-S1113]-[S483S465]-S876-S477-S979-S466-[S817-S61].

\section{Discussion}

Genetic mapping is very straightforward for simple Mendelian monogenic diseases. However, due to the complex genetic basis of BP spectrum disorders, linkage studies on loci involved in the disease etiology have proved very difficult. Therefore, a variety of approaches are being used to identify susceptibility genes for BP and for complex genetic disorders in general. ${ }^{29}$

Once suggestive linkage is found, replication studies have to be performed in order to confirm or reject the proposed candidate region. Linkage to chromosome $18 \mathrm{q}$ was found in several independent studies. ${ }^{15-21}$ Therefore, the $18 \mathrm{q}$ region might harbour a susceptibility gene for BP spectrum disorders. This was the starting point for our chromosome 18 genetic and physical mapping studies.

In our previous study, ${ }^{15}$ lod scores were calculated using diagnostic stability scores and complete penetrance for individuals of age 60 or older. Two healthy 
individuals in our pedigree have the disease haplotype and therefore reduced the initial lod scores. ${ }^{15}$ However, this model is too strict if other genetic or environmental modifiers of the susceptibility to BP spectrum disorder are involved. The assumption of other factors influencing disease penetrance is reasonable, because in many pedigrees non-affected but disease-transmitting carriers can be identified. Therefore, in this study, we not only tested several new markers in the chromosome 18q region but also analysed the data under three different disease models to make our lod score analysis more comparable with other studies. Maximum lod scores are obtained at zero recombination frequency with several markers, indicating that no recombinations have occurred between the disease and the specific marker genes, in the affected family members (Table 2). Although the lod scores do not reach the formal levels of statistical significance, simulation analysis suggest that a lod score of 2.01 (model1) is reached only in 19/10000 replicates assuming no linkage. We also observed in all affected individuals a common region derived from the affected parent. Moreover, based on two informative recombinants, we were able to reduce the $18 \mathrm{q}$ candidate region for $\mathrm{BP}$ spectrum disorder considerably from $15.2 \mathrm{cM}$ to an estimated genetic distance between 4.7 and $8.9 \mathrm{cM}$. A more accurate genetic distance could not be deduced since D18S346 is not mapped precisely. Also, no more genetic markers are available to reduce the region between D18S477 and D18S979.

In our analyses, we assumed that there is one major gene which causes the BP spectrum disorders observed in MAD31. This gene has a reduced penetrance, and there are no phenocopies in the family. However, it has to be kept in mind that these assumptions could be violated. Specifically, our candidate region is defined based on two individuals, of whom one has a diagnosis of MDD. Our candidate region would increase considerably if this individual were to prove to be a phenocopy. However, considering all data, this is the most interesting region for us to start mapping candidate genes for BP spectrum disorder.

We have compared maps based on our haplotype analysis, our STS content map, the WI integrated map, the Généthon genetic map, the Marshfield genetic map and some radiation hybrid maps. Despite some discrepancies, we derived a general order of the markers that is compatible with the order from different sources.

We constructed a YAC contig spanning our candidate region. During the construction of the YAC contig, several difficulties were encountered. Initially, three regions were observed with no overlaps among YACs (gaps). After narrowing the candidate region, two of these gaps fell outside the candidate region. Based on the end sequences of the YACs and YAC library screening, the remaining gap was closed. From our STS content mapping data, we observed that the refined candidate region is covered by 20 YACs. We constructed a minimum tiling path spanning our candidate region, consisting of three YACs: 961-h-9, 766-f-12 and $907-\mathrm{e}-1$. The size and stability of these YACs was confirmed by PFGE. Based on the sizes of these YACs, we estimated the maximal candidate region to be 4.8 megabases long. According to the recently published radiation hybrid map of chromosome $18,{ }^{27}$ the maximal region is $5.1 \mathrm{Mb}$ long. This region might contain about 100 genes, making it an enormous task to screen each of these genes separately. Therefore, we will try to refine further our candidate region, firstly by updating the diagnoses of the children of the affected individuals in family MAD31 and subsequently by trying to find new informative recombinants, secondly by applying linkage disequilibrium studies in the candidate region.

On the human gene map ${ }^{28}$ (http://www.ncbi.nlm.nih.gov/genemap), nine genes and 12 unidentified transcripts have been assigned within this candidate region. Four of these genes (maspin, CAP2, SCCA1, and bomapin) belong to the serine proteinase inhibitors or 'serpins', which are key regulatory proteins in biologic processes. Two genes (BCL-2 and FVT1) are possibly involved in B-cell chronic lymphocytic leukaemias and in follicular lymphomas. The function of the remaining genes (KIAA0606, HUR7, CDC42) is not well documented. None of these genes are strong candidates in the pathology for BP spectrum disorders, but they cannot be excluded. Several strategies will have to be applied to focus the search for the BP gene. Anticipation has been shown to occur in BP disorder, ${ }^{30}$ and expanding CAG repeats have been shown to occur in BP patients. ${ }^{31,32}$ Therefore, alternative strategies involve the search for expanded triplet repeat sequences by screening for their presence in cDNAs derived from brain libraries and located in our region. After further completion and detailed characterisation of the YACs spanning our candidate region, we will subclone the YACs comprising the minimum tiling path in an exon-trap cosmid vector. ${ }^{33}$ This cosmid library will be screened for known or new candidate genes and for genes containing triplet repeats. 


\section{Acknowledgements}

We would like to thank S Fauré and J Weissenbach for the prepublication release of the genetic map. This work was supported by a grant from the Fund for Scientific Research Flanders-Belgium (FWO), a special research fund of the University of Antwerp and EU grants BIOMED1 (CT 92-1217) and BIOMED2 (BMH4-97-2307 and BMH497-2466). GRV is a Postdoctoral Fellow of the FWO.

\section{References}

1 Tsuang MT, Faraone SV: The Genetics of Mood Disorders. The Johns Hopkins University Press: Baltimore, 1990.

2 Spence MA, Flodman PL, Sadovnik AD, Bailey-Wilson JE, Ameli H, Remick RA: Bipolar disorder: evidence for a major locus. Am J Med Genet (Neuropsychiat Genet) 1995; 60: 370-376.

3 McGuffin P, Owen MJ, O'Donovan MC, Thapar A, Gottesman II: Affective disorders. In: McGuffin P, Owen MJ, O'Donovan MC, Gottesman II (eds). Seminars in Psychiatric Genetics. Gaskell: London, 1994, pp 110-127.

4 Egeland JA, Gerhard DS, Pauls DL et al: Bipolar affective disorder linked to DNA markers on chromosome 11. Nature 1987; 325: 783-787.

5 Mendlewicz J, Sevy S, Brocas H et al: Polymorphic DNA marker on $\mathrm{X}$ chromosome and manic depression. Lancet 1987; 1: 1230-1232.

6 Baron M, Risch N, Hamburger R et al: Genetic linkage between X-chromosome markers and bipolar affective illness. Nature 1987; 326: 289-292.

7 Kelsoe JR, Ginns EI, Egeland JA et al: Re-evaluation of the linkage relationship between chromosome $11 \mathrm{p}$ loci and the gene for bipolar affective disorder in the Old Order Amish. Nature 1989; 342: 238-243.

8 Baron M, Freimer NF, Risch N et al: Diminished support for linkage between manic depressive illness and $\mathrm{X}$-chromosome markers in three Israeli pedigrees. Nat Genet 1993; 3: 49-55.

9 Blackwood DHR, He L, Morris SM et al: A locus for bipolar affective disorder on chromosome $4 \mathrm{p}$. Nat Genet 1996; 12: 427-430.

10 Craddock N, Owen M, Burge S, Kurian B, Thomas P, McGuffin P: Familial co-segregation of major affective disorder and Darier's disease (Keratosis Follicularis). Br J Psychiatry 1994; 164: 355-358.

11 Berrettini WH, Ferraro TN, Goldin LR et al: Chromosome 18 DNA markers and manic-depressive illnes: evidence for a susceptibility gene. Proc Natl Acad Sci USA 1994; 91: 5918-5921.

12 Straub RE, Lehnert T, Luo Y et al: A possible vulnerability locus for bipolar affective disorder on chromosome 21q22.3. Nat Genet 1994; 8: 291-296.

13 Pekkarinen P, Terwilliger J, Bredbacka P-E, Lonnqvist J, Peltonen L: Evidence for a predisposing locus to bipolar disorder on Xq24-q27.1 in an extended Finnish pedigree. Genome Res 1995; 5: 105-115.

14 Stine OC, Xu J, Koskela R et al: Evidence for linkage of bipolar disorder to chromosome 18 with a parent-of-origin effect. Am J Hum Genet 1995; 57: 1384-1394.
15 De bruyn A, Souery D, Mendelbaum K, Mendlewicz J, Van Broeckhoven C: Linkage analysis of families with bipolar illness and chromosome 18 markers. Biol Psych 1996; 39: 679-688.

16 Freimer NB, Reus VI, Escamilla MA et al: Genetic mapping using haplotype, association and linkage methods suggests a locus for severe bipolar disorder (BPI) at 18q22-q23. Nat Genet 1996; 12: 436-441.

17 Coon H, Hoff M, Hadley D et al: Analysis of chromosome 18 DNA markers in multiplex pedigrees with manic depression. Biol Psych 1996; 39: 689-696.

18 Edwald H, Mors O, Koed K, Eiberg H, Kruse TA: Susceptibility loci for bipolar affective disorder on chromosome 18? A review and a study of Danish families. Psychiatr Genet 1997; 7: 1-12.

19 Van Broeckhoven C, Verheyen GR: Summary report of the chromosome 18 workshop. Psychiatr Genet 1998; 8: 97-108.

20 McInnes LA, Escamilla MA, Service SK et al: A complete genome screen for genes predisposing to severe bipolar disorder in two Costa Rican pedigrees. Proc Natl Acad Sci USA 1996; 93: 13060-13065.

21 McMahon FJ, Hopkins PJ, Xu J et al: Linkage of bipolar affective disorder to chromosome 18 markers in a new pedigree series. Am J Hum Genet 1997; 61: 1397-1404.

22 Cottingham RW, Idury RM, Schaffer AA: Faster sequential genetic linkage computations. Am J Hum Genet 1993; 53: 252-263.

23 Rice JP, Reich T, Andreasen NC: The estimation of diagnostic sensitivity using stability data: an application to major depressive disorder. J Psychiatr Res 1987; 21: 337-345.

24 Hudson TJ, Stein LD, Gerety SS et al: An STS-based map of the human genome. Science 1995; 270: 1945-1954.

25 Silverman GA: Purification of YAC-containing total yeast DNA. In: Markie D (ed.). YAC Protocols. Humana Press: New Jersey, 1996, pp 65-68.

26 Foellmer O: Monochromosomal somatic cell hybrid panels: a valuable tool in genomics research. bioSolutions Newsletter 1995; 2: 1-3.

27 Giacalone J, Li X, Lehrach H, Francke U: High-density radiation hybrid map of human chromosome 18 and contig of 18p. Genomics 1996; 37: 9-18.

28 Schuler GD, Boguski MS, Stewart EA et al: A gene map of the human genome. Science 1996; 274: 540-546.

29 Kruglyak L, Lander ES: High-resolution genetic mapping of complex traits. Am J Hum Genet 1995; 56(5): 1212-1223.

30 McInnis MG, McMahon FJ, Chase GA, Simpson SG, Ross CA, DePaulo JR: Anticipation in bipolar affective disorder. Am J Hum Genet 1993; 53: 385-390.

31 Lindblad K, Nylander P-O, De bruyn A et al: Detection of extended CAG repeats in bipolar affective disorder using the repeat expansion detection (RED) method. Neurobiol Dis 1995; 2: 55-62.

32 Oruč L, Lindblad K, Verheyen GR et al: CAG repeat expansions in bipolar and unipolar disorders. Am J Hum Genet 1997; 60: 730-732.

33 Del-Favero J, Krols L, Michalik A et al: Molecular genetic analysis of autosomal dominant cerebellar ataxia with retinal degeneration (ADCA type II) caused by CAG triplet repeat expansion. Hum Mol Genet 1998; 7: $177-186$. 